\title{
Contribución al estudio y conocimiento de las aves rapaces de Colombia
}

\author{
Federico Carlos Lehmann Valencia
}

Rev. Acad. Colomb. Cienc. Ex. Fis. Nat. 1940, 3 (12): 455-461.

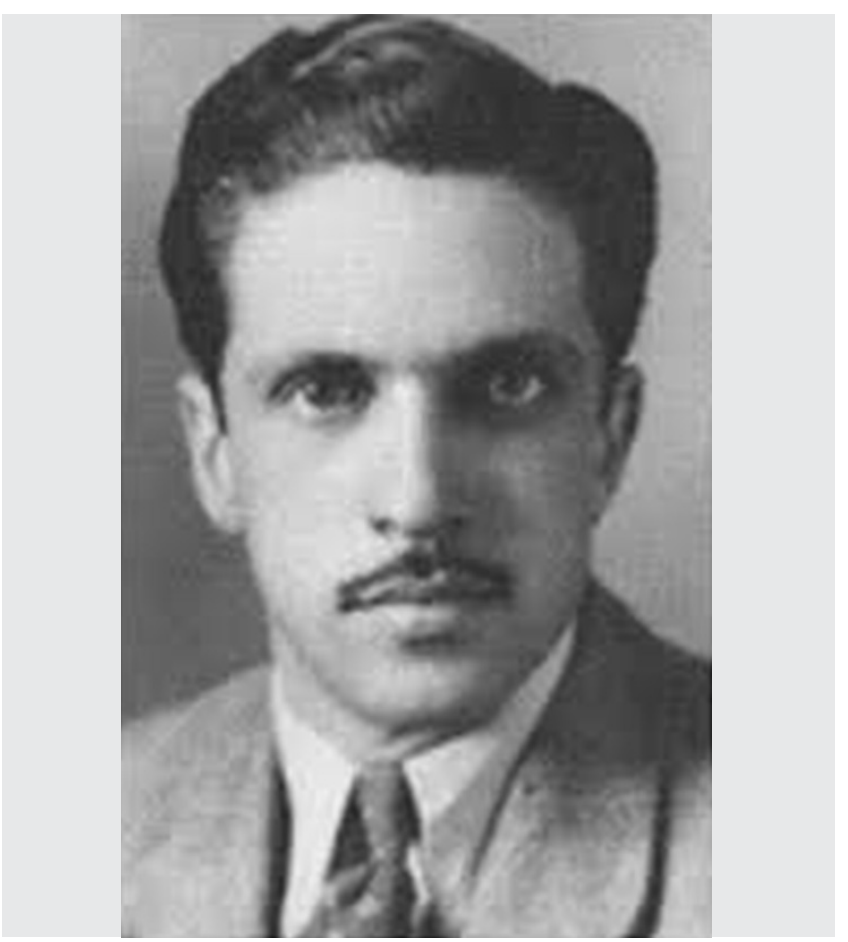

\section{Federico Carlos Lehmann Valencia (1914-1974)}

Federico Carlos Lehmann Valencia nació en Popayán, el 23 de marzo de 1914. Fue educado por su abuela quien le inculcó el espíritu naturalista y el amor por la geografía. Realizó sus estudios superiores en la Universidad del Cauca y los complementó en la Universidad Nacional, donde estuvo encargado de las colecciones animales, principalmente las de ornitología. Fue miembro del Consejo Internacional para la conservación de las aves y promovió desde allí la legislación para su conservación. Igualmente fue asesor del Ministerio de Agricultura en el Valle del Cauca, posición desde la cual lideró el control de la caza indiscriminada y creó varias áreas protegidas en el Suroccidente colombiano. Fundó los museos de Historia Natural de la Universidad del Cauca, del Departamental del Valle del Cauca (que recibió su nombre) y del Instituto de Ciencias Naturales de la Universidad Nacional. Obtuvo muchos reconocimientos en Colombia, Estados Unidos, Inglaterra, Japón, Francia y Bélgica por sus esfuerzos dirigidos al conocimiento y la protección de las aves.
Este artículo, escrito al final de los años 30, presenta la clasificación taxonómica de las aves pertenecientes al "orden Raptores" y señala las características de las principales especies conocidas hasta ese momento. El trabajo incluye una descripción de los caracteres morfológicos externos e internos que distinguen a este grupo, compara estas características con aves relativamente cercanas y separa los grupos conocidos hasta la época como sigue: Cathartiformes (buitres, rapaces carroñeros), Falconiformes (rapaces predadores) y Strigiformes (búhos y lechuzas). Presenta, igualmente, una amplia descripción de su distribución geográfica proporciona detalles de sus hábitos de vida, describe la ecología y la historia natural, resultantes la mayoría de ellas, de sus observaciones como naturalista. Presenta opiniones que confirman la utilidad de estas especies para confrontar la idea existente, en ese momento, estas aves eran animales peligrosos y perjudiciales para el ser humano.

Si bien está titulado como "Las aves rapaces”, el artículo publicado en el volumen 3 número 12, se concentra en los Cathartiformes. Además de las características generales, se presentan las principales especies con su nombre científico, los nombres comunes, las características taxonómicas con inclusión, en varios casos, de diferencias entre machos y hembras. Además, se presentan anotaciones sobre nidos y huevos, distribución geográfica y comportamiento de las especies más representativas incluyendo especies emblemáticas como el cóndor, el rey de los gallinazos, así como aquellas que son tan comunes como las gualas y los gallinazos. El libro incluye láminas correspondientes a dibujos de muy alta calidad que han servido de referencia para la mayoría de los trabajos de identificación y de listados de aves existentes en muchas regiones del país. Por la importancia del ornitólogo Carlos Lehmann y su obra sobre las aves y la importancia de su conservación en Colombia, la cual se ve reflejada en libros, artículos científicos y videos de divulgación, por lo que este artículo es considerado como uno de los clásicos publicados en la revista de la Academia Colombiana de Ciencias Exactas, Físicas y Naturales.

Jaime Ricardo Cantera Kintz, Ph. D. Miembro de Número 


\title{
CONTRIBUCION AL ESTUDIO Y CONOCIMIENTO DE LAS AVES RAPACES DE COLOMBIA
}

\author{
F. CARLOS LEHMANN V.
}

Jefe del Departamento de Zoologia del Instituto Botánico de la Universidad Nacional

\section{INTRODUCCION}

Si quisiéramos, como para los mamíferos, separar de otras aves aquellas que se alimentan de presas, no encontraríamos un solo Orden que no entrara en esta Clase.

La existencia de Familias y Ordenes cuyos miembros tienen una alimentación exclusivamente vegetal, es uno de los caracteres distintivos de los mamíferos; nada parecido se encuentra en las otras clases de vertebrados. Casi todas las aves son predatoras, $\mathbf{y}$ aún aquellas que parecen más inofensivas, como las aves cantoras, se nutren casi exclusivamente de animales y comen frutas y raices accesoriamente.

Generalmente admitimos un solo Orden de aves carnivoras y bajo esta denominación no están comprendidas las aves de mar $y$ de rio, que, sin embargo, se nutren casi exclusivamente de vertebrados.

En ciertas grandes divisiones de la Clase "Ares", divisiones que se consideran como Ordenes, el régimen animal consistente en presas vivas, se muestra con caracteres muy marcados. Todas las aves se nutren de otros animales y por excepción solamente de vegetales. Persiguen sus presas con encarnizamiento, en el aire o en el suelo, tanto en medio del follaje de los árboles, como en el seno del agua; las matan después de cogerlas, o se contentan con cadáveres que encuentran. Algunas comen frutas, 10 mismo que ciertos mamíferos carniceros, y ésta es una razón más para comparar a los carnívoros con las predatoras.

\section{ORDEN RAPTORES (RAPACES) - GENERALIDADES}

Por razón de sus costumbres rapaces, más que por sus caracteres físicos, estas aves han sido agrupadas en un Orden. Cada miembro de este Orden está provisto de un pico fuertemente ganchudo, con un área blanda en su base, llamada cera. Las únicas aves diferentes que poseen picos similares, son los papagayos, pero estos últimos tienen sus dedos dispuestos de una manera diferente, pues tienen dos dedos dirigidos hacia adelante $y$ dos hacia atrás, mientras que las aves rapaces tienen siempre tres dedos dirigidos adelante, como las águilas, o el dedo exterior pueden dirigirlo a voluntad al frente o atrás, como los buhos.

Dentro de este Grupo se han reconocido tres Ordenes: el primero es el de los Buitres americanos Cathartiformes, reconocido por muchos como un Orden aparte $y$ que se alimentan de carroña ; separados, además, de los otros, porque sus pies no son propios para despedazar presas viras, pues se alimentan de animales muertos o moribundos y porque tienen la cabeza y parte del cuello sin plumas. Este Orden incluve sólo una Familia. Tanto los individuos del segundo como del tercer Orden tienen la cabeza completamente emplumada. En el Orden de las rapaces diurnas Falconiformes, los ojos están a los lados de la cabeza, (aunque no en todas las especies), de tal manera que los dos ojos no miran siempre en la misma direccion. Inl tercer Orden es el de las rapaces nocturnas Strigiformes, aves que tienen los ojos dirigidos hacia adelante, de modo que ambos miran en la misma dirección y están rodeados por discos de plumas radiales. Las Estrígidas están divididas en dos Familias: las lechuzas y los buhos. Las Falcónidas incluyen tres Familias: las águilas, gavilanes y milanos; los halcones, caracarás y garrapateros; $\boldsymbol{y}$ las águilas pescadoras o mariuas Pandionidæ.

Caracteres-El tamaño de las rapaces varía; las hay que alcanzan casi la talla de las más grandes corredoras o de algunas aves acuáticas; otras no son más grandes que una alondra. Entre estos dos extremos se encuentran todos los intermedios posibles. A pesar de estas diferencias notables el tipo de la rapaz se conoce siempre.

No es muy difícil dar los caracteres generales de las rapaces. Su cuerpo se parece bastante al de los loros: es rechoncho; el pecho ancho, los miembros fuertes, aunque con frecuencia de una longitud casi desproporcionada; la cabeza es grande, redondeada, rara vez alargada; el cuello grueso, con frecuencia corto, algunas veces alargado; el tronco es corto y robusto; lo mismo que los miembros superiores e inferiores. Por consiguiente, se puede reconocer una rapaz aunque haya sido despojada de sus armas ofensivas y de su plumaje; pero estas armas, es decir, el pico $y$ las garras, son las que caracterizan verdaderamente a las rapaces.

Como antes dije, el pico de estas aves se parece al de los papagayos, pero no es globuloso, como el de los loros; es comprimido lateralmente, más alto que ancho; la mandíbula superior es inmóvil y recubre completamente a la inferior; los bordes son más cortantes, su gancho más agudo, y con frecuencia la mandíbula superior está armada de un diente agudo (como en los halcones).

Las patas se parecen a las del loro. Son cortas y fuertes los dedos son muy largos con relación a los tarsos; el dedo exterior puede, hasta cierto punto, ser dirigido hacia atrás : pero lo que distingue los pies de estas aves son las uñas, que forman una garra. Las uñas son fuertemente encorvadas, raramente aplanadas $y$ embotadas; su lado superior es convexo y el inferior ligeramente cóncavo, limitado por dos bordes casi cortantes.

Las plumas son ora fuertes $y$ rígidas, ora pequeñas, suaves, aún sedosas o lanosas. Ciertas partes de la cabeza son algunas reces desnudas, prineipalmente alrededor del ojo y en la región comprendida entre este órgano y el pico; en algunas especies el ojo está rodeado de un círculo de plumas radiantes, conocido con el nombre de disco. Las plumas de las alas y de la cola son muy grandes; su número es constante. Se cuentan diez en la mano, doce, $y$ generalmente trece a dieciséis, en los brazos, $y$ doce plumas cau dales dispuestas por pares. Como en los loros de organización más elevada, las rapaces más perfectas tienen las plumas pequeñas. En muchas especies, $\boldsymbol{y}$ esto es característico para las rapaces, los tarsos y aún los dedos están cubiertos, y las plumas de la pierna son con frecuencia bastante largas.

El plumaje es generalmente de color apagado, sin ser por esto desagradable a la vista. Hasta algunas especies son notables por la belleza de sus tintes. Las partes de la cabeza desproristas de plumas, los apéndices del pico de ciertas especies, la región óculo-nasal, el pico, las patas, los ojos, son frecuentemente de coloración muy riva.

En cuanto a los órganos interiores, el esqueleto es muy vigoroso: el esternón, como en todas las aves de vuelo sostenido, recubre casi toda la parte anterior del cuerpo; la quilla es muy desarrollada; los huesos de los miembros superiores son notables por su longitud: los de los inferiores por su solidez. Casi todos los huesos son huecos, es decir, desprovistos de tuétano, y están en comunicación con los órganos respiratorios. Los puimones son voluminosos y los sacos aéreos muy desarrollados. El esófago es muy dilatable, presentando frecuentemente repliegues en el interior, $y$ ofrece generalmente una especie de bolsa o buche. Fl estómago es grande, membranoso; el intestino varía en sus dimensiones. La lengua es ancha, redondeada en la parte anterior $y$ denticulada en los bordes de la parte posterior.

Entre los órganos de los sentidos, el ojo merece especial atención. Es grande, sobre todo en las rapaces nocturnas, $y$ presenta movimientos interiores muy completos, determinados por la presencia del peine, de lo cual resulta una acomodación de la rista, igualmente buena para distancias muy diferentes; lo mismo sucede con respecto a la intensidad de la luz por la facilidad de dilatar o contraer la pupila.

Los órganos del oído son bien desarrollados en las rapaces, de modo especial en los buhos.

Por el contrario, los órganos olfativos son en cierto modo rudimentarios, a pesar de que para los buitres, al menos, se ha sostenido lo contrario.

EI tacto es más perfecto en estas aves que el gusto y el olfato. Por lo general las hembras son de mayor tamaño que los machos y algunas veces de coloración algo diferente.

\section{DISTRIBUCION GEOGRAFICA}

Las rapaces habitan toda la tierra; se las encuentra en todas las latitudes, como en todas las alturas; de esto se hablara al estudiar cada especie en particular.

Costumbres y régimen-Las facultades intelectuales de las rapaces son muy desarrolladas. Si algunas se muestran estúpidas, las demás dan pruebas de inteligencia. La mayor 
EL REY DE LOS GALLINAZOS.

Sarcorhamphus papa (Linneo).

$$
\text { 1/8 del tam. nat. }
$$

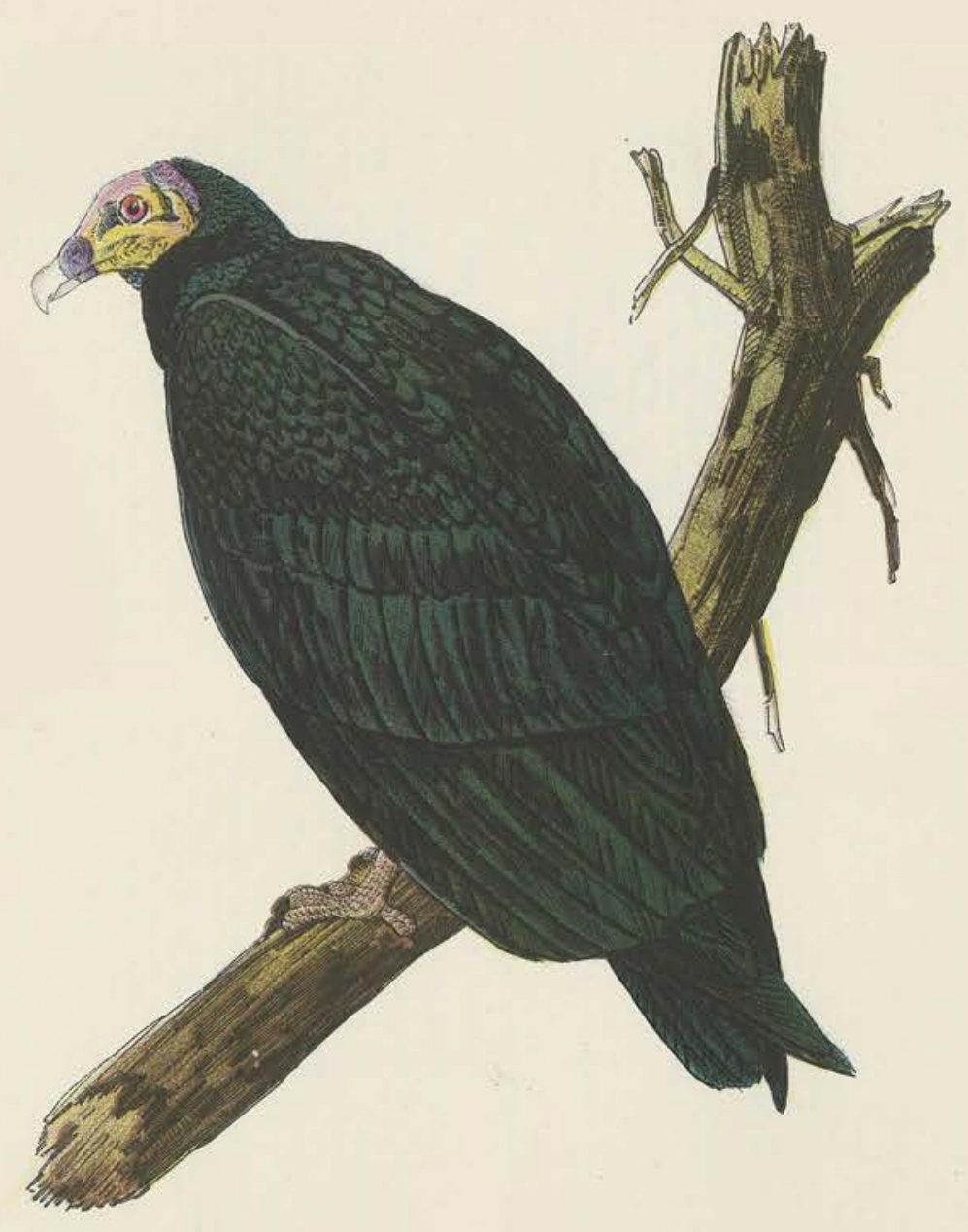

GUALA DE CABEZA AMARILLA.

Cathartes urubitinga Pelz.

$1 / 7$ del tam. nat. 
parte de las cualidades que se les atribuye las tienen en realidad: la conciencia de su fuerza, hasta una cierta grandeza; pero son crueles, feroces y atrevidas. No obran sino después de haber reflexionado, conciben planes y los ejecutan. Son adictas a sus compañeras; atacan con atrevimiento a sus enemigos. Los halcones de modo especial nos muestran hasta qué punto son capaces de desarrollar su inteligencia.

Las rapaces carecen de una cualidad propia de las aves: pues por lo general no tienen una voz agradable. Algunas no tienen más que dos o tres notas diferentes, $y$ aún son éstas muy discordantes. El águila arpía, por ejemplo, produce un graznido y un chillido desagradables. Esto no quiere decir que no existan algunas rapaces cuya voz sea agradable al oído.

Las rapaces en su mayor parte son aves arborícolas, habitantes de los bosques, pero no evitan ni las montañas peladas, ni el desierto. Se las encuentra en las islas más pequeñas del océano, así como en las cimas de las montañas más elevadas. Se las ve planear sobre las llanuras arenosas y calcinadas por el sol del desierto; también habitan las espesuras impenetrables de las selvas vírgenes, o los edificios abandonados de las ciudades. Cada especie tiene un área de dispersión muy extensa, pero que no está en relación con sus facultades de locomoción. Algunas habitan una localidad muy restringida, otras no conocen ningún limite $y$ recorren toda la tierra.

Muchas rapaces son migratorias y durante el invierno de las regiones boreales van al sur, siguiendo a los pajaritos, los patos, etc. En la época de emigraciones, las rapaces, como muchas otras aves, se reúnen en bandadas que son algunas veces bastante numerosas; el resto del tiempo viven aisladas o por parejas.

Fn Colombia, las rapaces, como la mayoría de las aves, no tienen época fija para anidar, pues esta época varía para cada región de acuerdo con la estación lluviosa, correspondiendo la postura casi siempre con el fin de las lluvias, de modo que los pequeños nacen al comienzo de la estación seca.

Su habitación o nido es variable. Generalmente se halla situado en un árbol, sobre el saliente o el hueco de una roca, o en la grieta de un muro; raramente en tierra. Todos los nidos colocados en los árboles o en las rocas son de construcción sólida; son anchos y bajos, al menos que hayan servido durante varios años, en cuyo caso, cada año, las aves los reparan, aumentando así su volumen. El interior es poco profundo. El macho y la hembra trabajan en su construcción. Las pocas rapaces que anidan en agujeros, se contentan con depositar sus hnevos en el fondo de la horqueta de un tronco, en el suelo o sobre una piedra desnuda.

El apareamiento va precedido de diversos juegos. Fl macho vuela soberbiamente; algunos dejan oír sonidos particulares, muy tiernos, una especie de canto. Los celos ejercen también su imperio; cualquier intruso es atacado y puesto en fuga; el esposo no tolera ni siquiera un ave de otra especie en su vecindad. Lstos combates tienen cierta majestad. Son revueltas súbitas, ataques rápidos, defensas brillantes, persecuciones mutuas, valientes resistencias. Los combatientes se cogen, se agarran, e incapaces para utilizar las alas, caen como en un torbellino. En tierra el combate cesa, para comenzar de nuevo a los pocos instantes en medio del aire. Después de una lucha prolongada, el vencido se retira perseguido por el vencedor, hasta más allá de sus dominios.

Por muy encarnizadas que sean estas luchas, es raro sin embargo, que terminen por la muerte de uno de los combatientes. La hembra sigue estos combates con interés, sin tomar parte sin embargo en ellos, y después de la fuga de uno de los rivales se abandona al vencedor.

Los huevos son redondeados; su cáscara es generalmente áspera; son enteramente blancos, grisáceos, amarillentos, o sembrados de puntos oscuros. Su número varía de uno a siete. Por lo general la hembra incuba sola ; pero en algunas especies el macho la releva de tiempo en tiempo. La duración de la incubación es de tres a seis semanas. En los primeros días los polluelos son seres redonditos, de cabeza grande, con ojos muy abiertos, cubiertos de un plumón grisblancuzco. Crecen rápidamente, y las plumas del dorso no tardan en aparecer. Los padres demuestran el más vivo cariño por su progenie $\mathrm{y}$ no la abandonan jamás: se exponen por ella al peligro $y$ a la muerte, si no se sienten bastante fuertes para defenderla. En tales circunstancias, pocas rapaces dan prueba de pereza; al contrario, la mayor parte despliega un atrevimiento y una temeridad notables. Muchos también transportan a sus pequeños a lugares más seguros. Los padres no son menos activos cuando se trata de nutrir a sus pequeñuelos. Les llevan más comida de la que son capaces de devorar. Al principio les dan los alimentos medio digeridos; más tarde presas que han despedazado. Aún después de haber volado, los jóvenes permanecen largo tiempo con sus padres, que les enseñan a volar, cazar, nutrirse y que continúan velando por su seguridad.
Vertebrados de todas clases, insectos de toda especie, huevos, gusanos, moluscos, excrementos humanos, raramente frutas, entran en el régimen de las rapaces. Se apoderan de animales vivos, roban sus presas a otros carnívoros, o se contentan con recoger los desperdicios que encuentran.

Cogen sus presas con las garras y las despedazan con el píco. Su digestión es muy rápida. En las especies que tienen buche, los alimentos permanecen algún tiempo en este órgano, donde son sometidos a la acción de la saliva; el resto es digerido por el jugo gástrico. Los huesos, tendones y ligamentos son reducidos a papilla. Las plumas y los pelos forman bolas que las aves regurgitan de tiempo en tiempo. Sus excrementos son una papilla bastante líquida y notablemente calcárea. Todas las rapaces pueden comer mucho a la vez y soportar abstinencia prolongada.

Además, las rapaces son buenas cazadoras; les damos el rango más elevado; las tenemos por nobles; sin embargo, hay excepciones en esta regla.

Exceptuando al hombre, tienen las rapaces pocos enemigos. Su fuerza y su agilidad son su salvación; pero son atormentadas por parásitos que se instalan sobre ellas en colonias numerosas. En suma, llevan una vida libre y feliz mientras el hombre no les declara la guerra.

Utilidad.-Según que las rapaces ataquen a seres que nos son nocivos o útiles, las debemos considerar como aliadas o enemigas. Exceptuando muy pocas especies, que deben perseguirse por la destrucción de otros animales que son útiles, las rapaces, en general, nos prestan grandes servicios.

Las rapaces fueron empleadas para la cetrería en Europa durante la Edad Media, y cuando este deporte llegó a su apogeo en Inglaterra, las diferentes especies eran usadas según el rango de las personas; así el gerifalte era usado por la realeza, el neblí por un conde o un marqués, el azor por un hacendado, el gavilán por un sacerdote y el cernícalo por un criado. De esta manera eran de una ntilidad inmediata, pero este deporte fue abandonado posteriormente por su crueldad; pero sin embargo ha sido practicado continuamente por los pueblos nómades del Asia Central rusa y en Africa. En la actualidad está volviendo a practicarse y en los Estados Unidos están amaestrando desde las más pequeñas especies de halcones, hasta el águila real y los buhos.

A los ojos de muchas personas, las rapaces que se conservan en jaulas no son de ninguna ntilidad. Pero no podemos dejar de reconocer los servicios que nos prestan diariamente, destruyendo tanto como pueden la funesta raza de los roedores $\mathrm{y}$ de los insectos. No es únicamente el Serpentario Secretarius secretarius que rompe la cabeza de la cobra, pues la gran mayoría de las rapaces son poderosas destructoras de reptiles, sin temor a los más venenosos. Los gallinazos se encargan de limpiar las calles de las poblaciones cuyos servicios higiénicos son deficientes. En los campos y en los bosques viven rapaces que merecen toda nuestra estimación. Nuestro deber sería protegerlas.

Aparte de estos servicios, la utilidad que aún pudieran tener para nosotros ciertas rapaces es mínima. La carne de la mayor parte no es comible, las plumas del águila solamente son estimadas en América por los indios, y en cantividad una rapaz no puede rendir más que servicios insignificantes. Tienen necesidad, para nuestro interés, de gozar de toda libertad.

Apuntaré algo de lo que dice Wetmore en "The Book of Birds", acerca de la persecución de las rapaces por el hombre, para dar una idea de lo mal que se hace al destruirlas:

La mano del hombre civilizado ha sido levantada universalmente contra la familia de las águilas $y$ aves de este grupo: son abaleadas o de cualquiera manera destruidas en toda oportunidad.

"Es raro, por tanto, para águilas que llegan a tiro de escopeta de un cazador que no reciban una carga de munición, $y$ en ciertas localidades las matan colocando trampas en los extremos de los postes que estas aves utilizan como perchas.

"La creencia en el espíritu de destrucción de las águilas es casi universal. Para muchos no hay distinción entre rapaces que habitualmente atacan pájaros y pueden destruír cierta cantidad de caza, y las especies perezosas de pesado vuelo, que se alimentan constantemente de ratones de campo $y$ otros roedores $y$ que por tanto son beneficiales para el hombre.

"Las comisiones de caza de muchos Estados han of recido subvenciones por las cabezas de las rapaces, $y$ han gastado cientos de miles de dólares en la destrucción de indecibles millares de ellas. El resultado es que en la mitad oriental de los Estados Unidos, éstas han disminuído a menos de una décima parte de su primitiva abundancia.

Desde que la disminución afectó las clases útiles, mucho más duro que aquellas clasificadas como nocivas, ha habido un aumento de roedores destructores, que antes estaban controlados por las rapaces, con el resultado que estos animales han hecho mucho daño a los intereses de la agricultura.

"Los cazadores han justificado la matanza sin distinción de rapaces, en el supuesto de que estaban conservando la 
eaza. En nuestros dias, con los Nature Lovers (Amantes de la Naturaleza) que no cazan y que igualan a los cazadores en número, puede darse alguna consideración a los derechos de aquéllos, que gozan viendo las águilas vivas y estudiando sus interesantes costumbres, además del valor que la mayor parte de estas aves tienen por sus hábitos alimenticios beneficiales.

"La acción debe ser dirigida contra las especies nocivas antes que contra el grupo entero, puesto que la matanza de la mayor parte de las rapaces, es un plan de acción tan disparatado, como sería la total destrucción de cualquier otro elemento que contribuya a nuestra prosperidad".

Entre las rapaces que pueden considerarse como nocivas en Colombia, la especie más notable es quizá el águila blanquinegra o real, Geranoaëtus melanoleucus meridensis, que habita en las rocas, de preferencia en los climas fríos de las cordilleras. El halcón peregrino o patero Falco peregrinus anatum, que ataca de preferencia a los patos, es únicamente accidental en nuestro país: $y$ el halcón palomero Faleo e. columbarius, que se alimenta casi exclusivamente de pajaritos, también es accidental o pasajero. De otras especies que pueden eausar algunos daños se tratarí al estudiarlas en particular.

\section{LOS BUITRES AMERICANOS O CATHARTIFORMES}

Se da el nombre de Catártidas a las aves que en el Nuevo Continente reemplazan a los buitres, siendo varias de sus especies llamadas buitres en algunas regiones.

Annque en apariencia exterior son semejantes a los buitres del Viejo Mundo y en un tiempo se los consideró como tales, al examinarlos con más atención vemos que poseen muchos caracteres que los diferencian de aquéllos, de tal manera que no hay lugar a confusión. "Dejándose guiar por este parecido han venido incluyendo los naturalistas a los cóndores y a las gualas entre las aves rapaces, sin más fundamento que el que pudiera haber para clasificar, en los mamíferos, los tapires al lado de los cerdos, o los gerbos con los canguros. Las últimas investigaciones sobre la anatomia de estas aves demuestran que están más cerca de las gresoras o de las tubinares que de los halcones, águilas y aúm de los verdaderos buitres, a los que se parecen en sus costumbres; por lo cual han venido a dar la razón al célebre Azara, quien en 1802, en sus "Apuntamientos para la Historia Natural de los Páxaros del Paraguay y Río de la Plata", formó con estas aves un grupo distinto de las de rapiña, describiendo minuciosamente algunos de los caracteres que los diferencian de éstas".

El carácter que distingue principalmente estos buitres de los del Antiguo Continente, es el tener los orificios nasales $\sin$ tabique divisorio; de esto resulta que se ve a través de la nariz hasta el otro lado en todas las especies. Otra característica notable que diferencia a las Catártidas de los verdaderos buitres es la de tener las patas mucho más débiles, con el dedo posterior muy corto $y$ situado un poco alto, además de las garras $y$ las uñas, que no son suficientemente fuertes, curvas $y$ afiladas, por lo cual estas aves no pueden capturar sus presas vivas $y$ menos despedazarlas con las garras. De tal suerte que para llevar el alimento a su polluelo, un cóndor por ejemplo, to hace en el buche vaciando luégo su contenido en el nido.

Como en los buitres europeos, africanos y asiáticos, la cabeza y el cuello son más o menos desnudos, frecnentemente de coloración muy viva, carácter éste que también las diferencia de la mayoría de los verdaderos buitres; pues en las Catártidas, si se exceptúa el gallinazo Coragyps atratus, todas las demás poseen coloraciones notables en las partes desundas del cuello y la cabeza, destacándose entre ellas por esto el Rey de los Gallinazos Sareorhamphus papa, en cuya cabeza y cuello contrastan el anaranjado, el rojo. el amarillo, el violeta, el gris y el negro.

En cuanto a los sentidos, sin duda alguna el de la vista es el mejor desarrollado, a pesar de que muchos sostienen que el olfato está también muy desarrollado.

Sobre la manera de buscar y encontrar su alimento las Catártidas hay diversas opiniones; sin embargo, la mayoría se inclina por la teoría de que estas aves encuentran su sustento por medio de su agudísima vista. Sobre esto llamo la atención a lo que dice el célebre ornitólogo norteamericano Dr. Alexander Wetmore en su libro citado atrás.

Personalmente agregaré a las sabias observaciones del Profesor Wetmore, algunas de las que sobre el particular he realizado yo, las cuales me han permitido comprobar que, no solamente las gualas, sino también los gallinazos, vigi lan constantemente a los perros en el campo, aprovechando de este modo el magnífico olfato del cánido que los guía dentro del bosque donde se encuentra un animal muerto. Relataré aquí solamente dos ejemplos para dar una pruebs más de que las catártidas en general encuentran su alimento principalmente por medio de la vista. Encontré nn día un ternero muerto debajo del bosque; cuando yo lo vi por primera vez ya tenía por lo menos $\mathrm{m}$ dia de muerto $\mathrm{y}$ por consiguiente un olor muy fuerte; sin embargo, no fue sino hasta el día signiente cuando llegaron los perros y detrás de ellos los primeros gallinazos. Otro ejemplo es el siguiente: Habiendo yo matado a tiros de revólver un caballo viejo, no bien me retiré cincuenta metros del sitio $\boldsymbol{y}$ me oculté para observar, cuando una guala que volaba en espirales a unos cinco kilómetros de distancia, al estar a suficiente altmra para poder ver desde allá el animal que yo acababa de matar, se vino con gran rapidez, y a los pocos minutos, cuando antes no se veía una sola, había más de cinco gualas, y no tardaron en llegar los gallinazos; como es natural, en un cuarto de hora no podía desarrollarse ningún olor en este animal, lo que indica que la primera lo localizó por medio de la vista, mientras que las otras y los gallinazos llegaron por observación mutua, pues es cosa sabida que todas estas aves se están vigilando mas a otras cuando están volando, y si alguna se dirige a tierra, las demás la siguen. Al contrario de las otras aves de este Grupo, las catártidas hembras no son más grandes que los machos.

\section{$\because *$}

\section{ORDEN CATHARTIFORMES}

\section{EL CONDOR}

Vultur gryphus Limmeo

Otro nombre: Buitre (con este nombre es designado en (asi toda Colombia).

Caraeteres.-Las dimensiones del cóndor varían, siendo los ejemplares peruanos y chilenos de mayor tamaño que los del Ecuador y Colombia. El macho tiene una longitud que varía de $1,10 \mathrm{~m}$. a $1,20 \mathrm{~m}$. y una envergadura que varía de $2,80 \mathrm{~m}$. a $3,20 \mathrm{~m}$.; la cola alcanza $38 \mathrm{cms}$. Ia hembra es un poco menor.

Gl macho adulto.-Tiene el plumaje negro, con algumos reflejos de azul acero con brillo metálico; las rémiges primarias de color negro mate; las rémiges secundarias de un negro grisáceo bordeadas exteriormente de blanco; las grandes coberteras del segundo orden, blancas sobre las barbas exteriores; la cola es negra, el occipucio, la cara y la garganta gris-negruzco; el cuello de color de carne lívida; la región del buche rojo pálido: un angosto lóbulo cutáneo que pende de la garganta y los dos pliegues verrugosos de los lados del cuello de $u$ rojo vivo; la base del cuello adornada por un collarin de plumas suaves blancas; el ojo color rojo de carmín; el pico de color cuerno claro; las patas café oscuro o negruzcas; posee una carúncula a modo de cresta sobre la base del pico $y$ la frente. La hembra no tiene cresta; la piel desnuda de la garganta es cafesosa ; el plumaje en general es negro café con matices cenicientos sobre las alas. El macho joven se parece mucho a la hembra en su coloración, con un tinte café-plateado más acentuado; no posee el collarín blanco, pero sí la cresta.

Nido y huevos.-El cóndor anida únicamente en rocas inaccesibles de las cordilleras, aprovechando una saliente o una hendidura; generalmente la hembra pone uno o dos huevos de color blanco amarillento, pintados algumas veces con manchitas pardas, al principio del año, sobre la roca desnuda o sobre una ligera capa de ramas secas. La incubación dura entre cinco y seis semanas, Los pequeños nacen cubiertos de un plumón blanco-gris; crecen lentamente, no pueden volar sino largo tiempo despnés de su nacimiento y permanecen aún bastante tiempo bajo el cuidado de sus padres.

Distribución.-El cóndor vive de preferencia en las partes más elevadas de la Cordillera de los Andes, desde e estrecho de Magallanes y Patagonia, hasta Colombia y el occidente de Venezuela. En el Perń y Chile baja hasta el nivel del mar. En Colombia es más escaso que en los países del sur, siendo raro verlo. Se ha observado en la Sierra Nevada de Santa Marta 5 la Cordillera Oriental hasta Mé rida (Venezuela). Fn la Cordillera Central habita desde las regiones del Puracé y Sotará al sur hasta el macizo andino del Ecuador. Algunos bajan desde Sotará por la hoya del río Ouileacé hasta el valle del rio Patía en el De partamento del Canca, donde no es raro verlos. Parece que antiguamente llegaban hasta el Valle del Canca, pero hoy nadie los ha visto más en esta región: también se los encuentra en las cercanías del Nevado del Ruiz, un poco al sur.

al cóndor figura ell nuestro escudo nacional, así como en los del Ecmador. Bolivia $y$ Chile: $y$ los antiguos incas lo tenian como animal sagrado.

El cóndor, como el "quebrantahnesos" de Europa, ha tenido la misma suerte: se les ha desconocido; se les ha acusado; se han escrito sobre ellas las historias más fabulosas y las han creído. Solamente en el siglo pasado se estableció la verdadera historia natural del cóndor. Unicamente después de Humboldt, Darwin, D'Orbigny y Tschudi, se ha conocido la verdad sobre esta ave fabulosa, hasta entonces.

Todas las costumbres del cóndor lo asemejan a los buitres. En las regiones donde es abundante vive en handa- 
das que suben hasta cuarenta o cincuenta individuos, pero eu la época del celo se separan por pares. En Colombia son gloumdantes solamente al sur, en el Departamento de Nariño, cerca de la frontera ecuatoriana y en la Sierra Nevada de Santa Marta (según F. Kraus). Cada pareja se instala en una roca $y$ permanece reunida. Por la mañana salen alrededor de las ocho y recorren su dominio, cuya extensión es difícil de imaginar. Se elevan primero lentamente, o planean a lo largo del cañón de rocas donde habitau; como todas las grandes vultúridas, se eleran describiendo círculos inmensos, y de esta manera llegan a enormex alturas que algunos calculan en 3.000 metros sobre las más altas cumbres andinas, es decir, unos 10.000 metros sobre el nivel del mar. Según Humboldt, se les ve con frecuencia planear por encima del Chimborazo, bastante arriba de las nubes y a una altura que él ha calculado en más de 7.000 metros. Su habitat favorito lo forman las más altas cordilleras, de preferencia en una zona de 2.000 a 5.000 metros sobre el mar. En el estrecho de Magallanes y Patagonia llegan hasta la orilla del mar $y$ anidan en los acantilados escarpados cuyo pie está baũado por las olas. En el Perú y en Chile descienden con frecuencia hasta las costas ; según Tschudi, son diez veces más abundantes en las alturas que en la llanura. Por lo general se ve al cóndor solo o por grupos de tres a cinco; cuando uno de ellos percibe alguna presa, cierra las alas $y$ se deja caer $y$ todos los demás le siguen.

Cuando su caza ha sido satisfactoria, regresan a su roca al medio día, donde reposan algunas horas; por la turde vuelven en busea de alimento. Fl condor se nutre principalmente de carroña, $y$ al decir de los indios, es el primero que llega donde está un animal muerto, pero que rehusa comer si va lo han empezado los gallinazos. Humbolkt dice que entre dos cazan al ciervo de los Andes, la vicuña $\mathrm{y}$ aún el guanaco $\mathrm{y}$ los terneros. Ellos fatigan a estos animales golpeándolos con las alas o picándolos, hasta que cayendo extenuados no pueden levantarse $y$ se convierten en la presa de esta ave. Con frecuencia también en sn huida esos animales se despeñan por los precipicios y luégo baja el cóndor a devorarlos en el abismo. Acompa. ñan al puma en sus excursiones para devorar los restos de sus comidas. "Cuando los cóndores bajan, dice Darwin, y en seguida todos vuelan súbitamente, el chileno sabe que hay allá un puma que vela por su presa $y$ persigue a esto ladrones". En nuestras regiones visitadas por el cóndor solamente están en peligro los terneros recién nacidos, los que son atacados por estas ares con relativa frecuencia. Arugue el cóndor en nuestro país es escaso, y sumamente arisco. puedo relatar el caso de un campesino, que al ver que un cóndor estaba matando a un ternero reciśn nacido, fue a espantarlo, siendo perseguido $y$ ahuyentado por el enorme pajarraco. En la orilla del mar se nutren de los grandes mamiferos marinos que las olas han dejado sobre la playa. Ellos evitan la vecindad de las poblaciones. Jamás atacan a los niños. Ordinariamente no comen más que carne muerta que desgarran sólo con el pico.

Los cóndores empiezan a devorar una presa por las partes que les ofrecen menor resistencia: los ojos, las orejas, la lengua $y$ las partes blandas alrededor del ano, donde hacen un gran agujero para penetrar en la cavidad abdominnl. Cuando se han reunido varios alrededor de un eadáver, los orificios naturales no son suficientes para permitirles cómo saciarse rápidamente; entonces practican aberturas en el vientre o el pecho con su fuerte pico. Los indios pretenden que el cóndor conoce perfectamente el sitio del corazón y que es éste el órgano que busca primero.

Cuando está lleno es pesado y perezoso; si se le obliga a volar, vomita los alimentos que llenan su buche. De est: costumbre se aprovechan mnchos para capturarlo. Poniendo um animal muerto en un corral, dejan que el cóndor se llene y lnégo lo acosan antes de que pueda vomitar: en otros lugares matan una bestia vieja en un sitio visible y regresan al día siguiente, cuando estando estas aves ahítas no preden volar, alcanzíndolas a caballo, pues, como es sabiclo, el cóndor necesita correr para poder despegar en terreno llano.

Estas aves son muy fnertes y no es fácil matarlas con una escopeta ordinaria, sino que es necesario emplear un rifle de una buena fnerza. Es la más fuerte de este (irmpo.

En cautividad el cóndor se comporta de diferentes maneras: algunos se domestican con facilidad, otros permanecen siempre salvajes $y$ picaros. "Tschndi poseí uno que se defendía vigorosamente cuando se lo quería tocar y que arrancó completamente una oreja al negro encargado de cuidarlo".

Los cóndores del Zoológico de Hamburgo no demuestran al hombre el menor afecto; varias veces han tratado de morder a su guardián. Hackel, por el contrario, tuvo largo tiempo dos de estas aves que eran agradables: "Su suavidad, dice el conde Gourcy, es increíble; su inteligencia, su juicio no son menos notables. Le han tomado afección a su amo, el macho sobre todo, $y$ al verlo no deja de saltar en la jaula; a su orden, se sube a la percha, viene a posarse sobre su brazo, se deja llevar por él, le acaricia la cara con el pico; él por su parte le mete el dedo en el pico, le tira de las plumas, juega con él como con un perro".

-La hembra no tarda en ponerse celosa de estas caricias v tira a su amo por el vestido, hasta que le da de comer. Ellos son muy celosos el uno del otro, y frecuentemente rasgan los vestidos de su amo tirando cada uno de su lado. El macho salta felizmente de una parte a otra como un niño: juega con todo. Estos cóndores difieren de todas las rapaces por su mansedumbre y alegria". Agregaré a este relato observaciones personales sobre un ejemplar cautivo que responde al nombre de Lindbergh, el cual es muy agradable; juega a los toros cuando se le muestra un pañuelo; corre como lo bacen los perros acostumbrados a esta clase de juegos. Se muestra muy contento cuando se lo acaricia, y él responde de la misma manera con gran suavidad, usan-
do el pico, y demuestra gran afecto hacia su dueño, el señor Emilio Cardoua. Este es un ejemplar macho que pasa poco de los tres metros de envergadura

Entre los campesinos y los indios existe la creencia de que el corazón del cóndor, o buitre, como ellos lo llaman, crudo o seco $y$ redncido al polvo es un gran remedio para la epilepsia, la anemia $y$ la debilidad general, $y$ la sangre $y$ pulmones son empleados para combatir la tuberculosis: la mucosa del estómago sirve de tópico para los cánceres del seno $y$ algunos afirman haber observado muy buenos resultados. Esta creencia riene desde los Incas y hoy se conserva desde Cinile hasta Colombia, pues a mi me fue encargado el cuerpo de un cóndor, con ese objeto, al saberse en Puracé (Canca) que so habia ido con intenciones de cazar alguno.

\section{EL REY DE LOS GALLINAZOS}

Sareorhamphus papa (Linneo)

Otros nombres: Rey zamuro, rey chulo, gallinazo rey, buitre real, cóndor blanco, alguacil, etc.

Caracteres.-La envergadura del rey de los gallinazos es de $1,80 \mathrm{~m}$. a $1,89 \mathrm{~m}$.; su longitud, de $0,88 \mathrm{~m}$. a $0,94 \mathrm{~m}$., de los cuales 0,25 corresponden a la cola.

Ambos sexos son semejantes-Adultos.-I La cabeza y el cuello son casi desnudos $y$ de coloración muy viva $y$ variada. La cabeza es negra con la parte superior de la frente de color grisiceo, la coronilla es rojo bermellón, los repliegues de las mejillas grises con matices violáceos; los repliegnes de la región auricular grises, tornándose anaranjados en la región occipital: un grueso repliegue de piel a lo largo de la nuca de color amarillo-cromo; los lados del cuelio de color rojo-cinabrio que se torna púrpura en la región occipital: la garganta es amarillo-cromo-claro: la barba violácen: las carúnculas que rodean la base del pico y la nariz anaranjadas; el pico es negro en la base, rojizo en el centro $y$ blanco amarillento en la punta; el iris es blanco puro; los párpados rojo-claro rivo. Toda la cabeza y la nuca están sembradas de cortas plumas en forma de cerdas de color negro. La parte desnuda del buche es de color rosado de carne. El collarín que rodea la base del cue llo es de plumas de color azul plomizo; la espalda, la región escapular y las coberteras superiores de las alas de hermoso color crema o ante claro. Las grandes eoberteras, las secundarias $y$ las primarias son negras con reflejos verdes o azules de brillo metálico; los bordes exteriores de las secundarias son de color crema o blanco sucio. La cola es igualmente negro brillante; el pecho, el vientre, los flancos, las piernas y las coberteras superiores de la cola son negras. Ias patas son grises-negruzeas; las uñas negras Las carúnculas de la base del pico son un poco más desarroliadas en el macho que en la hembra. Los dedos del frente están reuniclos en su base por una corta membrana, más desarrollada entre el dedo exteriox $y$ el medio, que entre éste $y$ el tercero. El dedo posterior o pulgar es corto. En general, las patas del rey de los gallinazos se parecen a las del cóndor, pero no tienen el dedo medio tan desarrollado en relación a los otros como éste.

Joven.-Los jóvenes son de un color pardo oscnro, casi negro, más o menos uniforme, algo más oscuro en la espalda: sembrado en la parte inferior de pequeñas manchas blancas que aumentan a medida que avanza en edad, lle gando a su coloración definitiva antes que la parte crem: de la espalda. La cabera es de tonos oscuros y las carúnculas tardan algín tiempo en desarrollarse. El iris es de color gris perla.

Nido y huevos.-Según Burmeister, el rey de los gallinazos anida sobre los árboles más elerados de la selva, y también construye su nido en la cima de los troncos secos. Los hnevos, que son ovalados, tienen $81 \mathrm{~mm}$. de largo y $66 \mathrm{~mm}$. de ancho. Tienen un fondo de color blanco-amarillento, manchados de eastaño oscuro o rojo de óxido, que algunos comparan a manchas de sangre: sin embargo, otros dicen que son completamente blancos. 
Distribución.-El rey de los gallinazos habita en todas las regiones bajas de América desde el $32^{\circ}$ sur en el Brasil y norte de Argentina, hasta México. Nunca pasa su habitat de una altura mayor de $1.500 \mathrm{mts}$. sobre el nivel del mar. En Colombia es bastante frecuente en la hoya del río Magdalena, en el litoral caribe $y$ en los Llanos Orientales, menos frecuente en la hoya del río Canca $y$ no ha sido observado en el valle del río Patía. También ha sido observado con relativa frecuencia en las selvas del Vaupés. Sin embargo es un ave bastante rara.

Al contrario de la generalidad de los buitres, el rey de los gallinazos es un habitante casi exclusivo de los bosques, siendo muy raro verlo en campo abierto. Según Azara, Humboldt, el Príncipe de Wied, D'Orbigny, Schomburgk, Tschudi y otros naturalistas que escriben sobre sus costumbres, es un ave que frecuenta las selvas vírgenes $y$ las llanuras cubiertas de bosques; jamás se lo encuentra ni en las estepas, ni en las montañas desnudas. Según D'Orbigny, es solamente la mitad de común que el cóndor; diez veces más raro que la guala $y$ quince veces más escaso que el gallinazo, pero yo creo que es aún mucho más escaso.

Se dice que pasa la noche en las ramas bajas de los árboles en el lindero del bosque, aunque to he olservado sobre la copa del árbol más alto y a bastante distancia de la orilla del hosque durante varios días consecutivos, llegando a busca su dormidero a las cinco $y$ media más o menos. Parece que tiene preferencia por lugares determinados $y$ se ve a varios de ellos reunirse alli al llegar la noche. Sólo o en sociedad, se eleva por la mañana mucho más temprano que el cóndor, probablemente debido a la diferencia de climas de las regiones que ellos habitan; recorre el bosque $y$ sus alrede dores buscando si un jaguar ha cazado algo para él. Cuando percibe algún cadáter, desciende con rapidez, pero sin abordar inmediatamente su presa; por el contrario, se poss a alguma distancia sobre un árbol o en el suelo: mete la cabeza entre los hombrus y de tiempo en tiempo echa sobre su presa una mirada llena de ansia. Se diría que se ejercita en excitar aún más su apetito por la vista. Por lo genera es únicamente al cabo de media hora que trata de satis facerlo. Es siempre prudente $y$ empieza por asegurarse de que nada lo amenaza. Con frecuencia come hasta el punto de que puede moverse con trabajo.

El rey de los gallinazos exhala un olor insoportable cuan do tiene el buche lleno; cuando está vacio, tiene como toda las catártidas $\mathrm{um}$ fuerte olor a almizcle. Cuando termina su comida se sube a $\mathrm{m}$ árbol vecino para hacer allí su digestión.

D'Orbigny asegura que ataca a los animales jóvenes, pero ningúm otro observador bace mención de este hecho.

Por lo general, cuando los gallinazos y las gualas están devorando algúm cadáver $y$ aparece el rey de los gallinazos todos se retiran para dejarle el campo libre, permaneciendo a prudente distancia. De esto han surgido las más raras leyendas sobre esta hermosa ave, y quizá a esto y a su notable figura debe su nombre.

Muchos observadores atestiguan el hecho antes mencionado, y Schomburgk dice: "Centenas de gallinazos están reunidos en torno de una carroña, pero todos se retiran desde que aparece su rey. Subidos en un árbol vecino o simplemente posados en tierra, esperan con los ojos brillantes de ansia $y$ de envidia a que su tirano haya calmado el hambre $y$ se haya retirado. Apenas ha terminado su comida cuando todos se precipitan para lograr la mejor parte de sus restos. Yo he sido con frecuencia testigo de este hecho $y$ puedo asegurar que delante de ninguna otra ave las pequeñas catártidas abandonan su presa como to hacen delante de su rey. Desde que éste aparece a lo lejos, todos se retiran, por ocupados que estén". Observaciones semejantes han sido hechas en todas las regiones en que existe el rey de los gallinazos en Colombia.

Tschudi ha pnesto en duda el relato de Schomburgk: ni él ni su amigo Stephan han observado conducta parecida. y Schomburgk recha\%ó al parecer victoriosamente esta critica, pues todas las pequeñas rultúridas se comportan de la misma manera en presencia de las grandes y aquí el América sucede lo mismo con el cóndor; pues se trata no de mua veneración, como suponen algunos, sino del respeto y temor al más fuerte.

Mis observaciones sobre este punto son en cierto modo contradictorias, pues observé parados en la mísma rama de un pequeño chaparro, que no tendría más de un metro de longitud, a m rey de los gallinazos joven $y$ a sus lados a un par de gualas, lo cual demuestra el poco temor que le inspiraha. En una carroña donde estaban reunidos alre. dedor de unos sesenta gallinazos y gualas, también habín cinco reyes que estahan distribuidos en la forma siguiente: uno de ellos hacía el papel de centinela en un chaparro recino, otro estaba parado a pocos metros de la carroña en el suelo, mientras los tres restantes estaban dándose el gran banquete en medio de sus parientes más pequeños, sin que estos demostraran mayor temor; antes bien, comían alounos de éstos al mismo tiempo. Cuando se alarmaron por mi presencia, el primero en volar fne el rey que se hallaba en el árbol, después el que estaba separado y por último los tres regios comensales $y$ con ellos los gallinazos y gualas, empezando a describir circulos sobre su interrumpida mesa; algumos de los gallinazos $y$ mo de los reyes fueron a posarse en los altos árboles de $\mathrm{m}$ bosquecillo cercano, mientras los otros regresaban para continuar su nauseabundo Pestín.

La mayoría de los observadores convienen en que el rey de los gallinazos es un ave sumamente maliciosa $y$ arisca. Al respecto puedo decir que en este caso, como en la mayoria de las aves, es uma cosa muy relativa que depende unicamente de la persecución de que sean victimas en las distintas regiones, pues mientras en el Valle del Canca es muy difícil acercarse a uno de los pocos que allá se pueden rer, en los Llanos del Meta son muy mansos, y yo he podido estar debajo de un árbol donde había dos de ellos, en el hosque, observándoles largo rato, y después de haber matado uno de ellos con un tiro de escopeta, el otro aún permaneció en el mismo árbol, viniendo a observar a su compañero muerto desde la misma rama de donde acababa de carer.

En cantividad se comportan como la mayoría de los buitres; son dóciles $y$ algunos muy agradables, atienden cuando se les llama por su nombre $y$ son juguetones, pero desconocen a los extraños $y$ entonces se sirven de sn fuerte pico para quitarlos de su lado. De un bello par de ejemplares que josee el Instituto Botánico, uno de ellos sobre todo es muy manso $y$ da muestras de alguna inteligencia, pnes contesta con un graznido peculiar cuando se le llama y acude en seguida. Este ejemplar ataca a sus compañeros de cantiverio más pequeños, especialmente cuando están enfermos, habiendo matado a dos águilas que estaban heridas. Demuestra gran predilección por pequeños animales y come con gran gusto pajaritos de los que se dan a las ágnilas, pero es incapaz de cogerlos si están vivos.

$$
* * *
$$

\section{EL GALLINAZZO}

\section{Coragyps atratus fotens (Lichtenstein)}

Otros nombres: chulo, zamuro, galembo, chicora, cuervo, golero, etc.

El gallinazo es la más común de las Catártidas; su color general es negro intenso.

Descripción.-La envergadura del gallinazo varía de $1,3:$ $\mathrm{m}$. a $1,40 \mathrm{~m}$.; su longitud es de $0,65 \mathrm{~m}$. a $0,68 \mathrm{~m}$., de lo cuales $0,18 \mathrm{~m}$. corresponden a la cola. El gallinazo tiene la cabeza y parte del cuello desnudos y la piel de estas partes de un color negro mate o gris-pardusco opaco, bastante arrugada, especialmente a los lados del cuello, y sembradas de cortas plumitas negras en forma de pelos, más abundantes en la región de la coronilla. Este género numca tiene coloraciones vivas en la piel de la cabeza y ei cuello. El pico es bastante largo, relativamente delgado y está cubierto por la cera hasta adelante de la nariz, que está situada bastante adelante $y$ es de forma alargada $y$ sin tabioue divisorio. La punta del pico es córnea y notablemente ganchuda, provista de bordes muy cortantes; la parte anterior de la mandíbula superior es notablemente levantada, por lo que se nota una depresión en la mitad del pico, gne es en esta parte casi cuadrado. Las plumas avanzan más arriba en la nuca que en Ia garganta, siendo más bajas en los lados inferiores del cuello. Los ojos son muy vivos y de color castaño rojizo-oscuro. Las patas son gris negruzcas con tarsos bastante altos de $71 / 2 \mathrm{cms}$. de longitud, cubiertas por escamas pequeñas, más grandes en la parte anterior que en la posterior. Los dedos son largos, siendo el del centro de mos 8 cms., mientras que los laterales, de igual tamaño ambos, sólo tienen $5 \mathrm{cms}$. Ll dedo posterior, que solamente tiene 2 cms., está, como en las dos especies anteriores. situado un poco alto. Los dedos anteriores están reunidos en su base por uma membrana igualmente desarmollada a ambos lados del dedo medio. Las unas son color de cuerno negro, poco curvadas y muy agudas. En general, las patas del gallinazo tienen la misma forma que las del cóndor. Fl plumaje es de color uniforme, negro intenso, con brillo me tálico verdoso o violeta. Las rémiges primarias tienen el raquis completamente blanco, asi como las barbas por el lado inferior, que son de un color blanco sucio, más extendido hacia la base $y$ sobre las harbas del lado exterior: en el extremo estas plumas son de color café-negro mate en sil lado inferior, mientras que en el lado superior son casi completamente negras en la punta $y$ de color pardo mate, bastante claro, hacia la base. Las 667 primeras rémiges son recortadas en ambos lados: la mís larga es la cuarta, y la primera la más corta y easi del largo de la sexta, pero sin embargo no se nota nna gran diferencia de longitud entre ellas, por lo cual parece como cuadrada la punta del ala en el vuelo. La caracteristica de las primarias blancuz- 

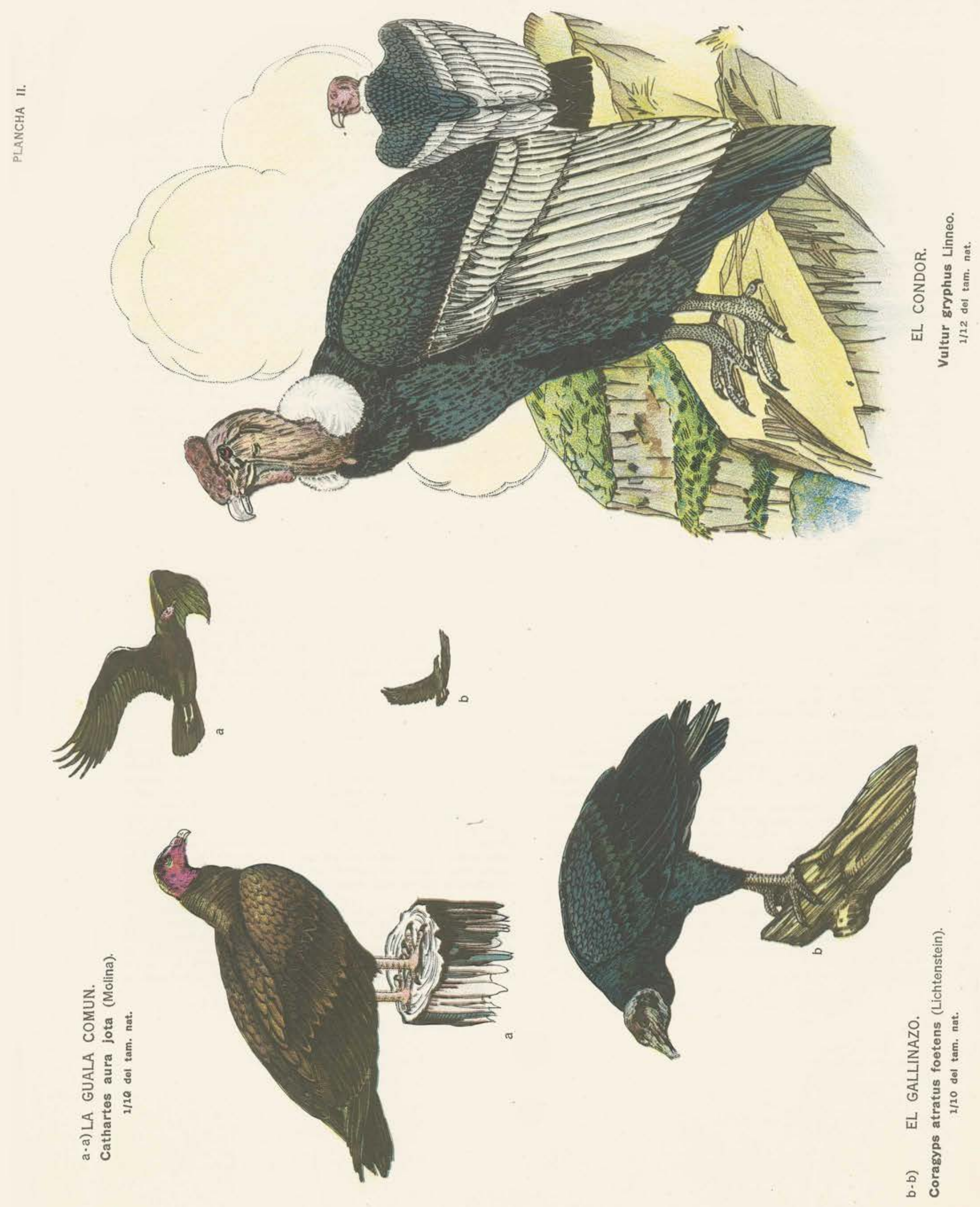
cas es muy notoria aún en el vuelo, por lo cual se reconoce en seguida aún a cierta distancia.

El gallinazo es un ave relativamente pesada; a pesar de tener una envergadura menor que la guala, es bastante más pesada que ésta.

Nido y huevos.-Los gallinazos anidan de preferencia en el suelo, sin construír un nido especial, debajo de un matorral $o$ al pie de un tronco; algunas veces anidan en agujeros de los barrancos o en la saliente de alguna roca; también suelen anidar en los zarzos, debajo de los tejados. Por lo general no hacen un nido cuidadoso, sino que se contentan con unas pocas chamizas para uniformar el piso cuando está designal. Ponen de uno a tres huevos de coloración blanco rerdoso o blanco azulado, manchados de puntitos castaños o rojizos, más abundantes en el extremo más ancho. Los jóvenes nacen desnudos, pero no tarda en aparecer un plumón de color crema sucio, que se desarrolla rápida. mente. Esta especie, como la mayoria de las aves en nuestro pais, no tiene época fija para anidar $y$ corresponde generalmente con el final de las lluvias, de suerte que los pequeños nacen al comienzo de la estación seca.

El gallinazo habita toda la América tropical y subtropi tal, desde el sur de los Estados Unidos hasta el norte de la Argentina, y desde la Isla de Chiloé al oeste, hasta el $40^{\circ}$ de longitud en el Brasil. Existe otra subespecie Coragyps atratus atratus que es la que ocupa el área septentrional de su dispersión desde Panamá al norte, aunque también se encuentra en Colombia. Se lo encuentra en todos los climas, pero es más frecuente en los climas cálidos, y muy escaso en los páramos. Frecuenta las poblaciones $y$ las vecindades de las casas de campo.

Los gallinazos son aves muy útiles en el campo, $y$ en las ciudades cuyos servicios sanitarios son deficientes; sin embargo, en muchas regiones son perseguidos por creerlos portadores de muchas enfermedades, pero últimamente se ha comprobado en los Estados Unidos que esto no es cierto.

En ciertas poblaciones de Colombia donde se aprovechan las aguas lluvias son destruídos por ensuciar los tejados o techos, pero esto se evita mucho más efectivamente que matándolos, poniendo un alambre templado a unos $15 \mathrm{cms}$ de altura sobre las partes más altas de los techos y sobre las aristas, que son las partes más frecuentemente empleadas como sitios de descanso por estas aves.

Por lo general, los gallinazos son rara vez molestados debido a sus servicios sanitarios, $\mathbf{y}$ en algunas partes viven como aves domésticas, sin temor al hombre, $y$ apenas se mueren cuando uno pasa por su lado. Cuando hay una carroña, se reúnen centenares de ellos $y$ en poco tiempo dejan los huesos completamente limpios. Durante su comida pelean unos con otros, y como generalmente ocurre que son las gualas las primeras en llegar donde hay un anima muerto, ellos las observan continuamente $y$ las siguen, cuando ellas se dirigen a tierra, pero como son más fuertes, las ahuyentan en seguida.

Como todas las catártidas, el gallinazo es un gran volador. Su vuelo es muy potente y sostenido. En los días claros ruela desde muy temprano $y$ solo o en bandadas se remontan a gran altura describiendo círculos, y gracias a su gran poder risual, localizan su alimento, descendiendo vertiginosamente, algumas veces con las alas cerradas $y$ produciendo un ruido particular. En los días lluviosos permanecen casi inactivos reunidos en sus dormitorios, $y$ si estái en el aire cuando se aproxima una lluvia, en seguida bajan con gran rapidez $y$ busean un lugar donde reposar mientras pasa el chubasco.

Esta especie se distingue de la siguiente por su coloración más oscura, su forma más robusta y la posición de las alas en vuelo, que no es curvada, sino más bien con las punta dirigidas hacia adelante; además porque las rémiges primarias son de coloración más clara, pareciendo a primera vista como blancas, La cola es muy corta y como recortada, por lo cual cuando la tienen cerrada parece cuadrada. Al aletear lo hacen con rapidez y dan unos tres a ocho aletazos seguidos de una más o menos larga planeada; pero una ve a bastante altura, vuelan durante horas enteras, sin move más que ligeramente las alas para adaptarlas a las condi ciones de las corrientes de aire. Los gallinazos son de las pocas aves, si no la única de este Orden, que comen frutas. Yo $\operatorname{los}$ he visto reunirse en los árboles de aguacate en las épocas de cosecha $y$ comer sus frutos hasta que no pueden volar.

Nunca atacan a otras aves para comerlas, pero sí acaban de matar a los animales enfermos o moribundos, euando éstos no se pueden parar, sacándoles los ojos y picoteándolos alrededor del ano.

Su voz es un gramido gutural, que se oye a alguna distancia cuando juegan o cuando pelean. Acostumbran reunirse en gran número en los sitios elegidos para dormir $y$ no es raro ver más de 40 de ellos en in solo árbol. En cambio, nunea anidan en colonias. sino por parejas $y$ muy lejos un nido de otro. Anoto como dato curioso que en las regiones del Vaupés unnca vi un ave de éstas; en cambio se las ve a to largo del Caquetá, el Putumayo y el Amazonas.

Estas ares nunca llevan alimento a sus polluelos en el pico o las patas, sino que los alimentan por regurgitación.

\section{LA GUALA COMUN}

Cathartes aura jota (Molina)

Otros nombres: guala de cabeza roja, guale, aura-jote, zonchiche, zamuro, chicora, chulo, galembo, ete.

La guala es, después del gallinazo, la catártida más común en Colombia.

Su coloración general es la de café muy oscuro, con la cabeza rojiza.

La envergadura de la guala común es de $1,72 \mathrm{~m}$. a 1,80 $\mathrm{m}$. : su longitud es de 0,67 a $0,76 \mathrm{~m}$., de los cuales $0,26 \mathrm{co}$ rresponden a la cola.

La eabeza y parte del cuello están cubiertas por una piel rugosa de coloración muy vira y parcialmente desnuda, sembrada de cortas plumitas negras en forma de pelos distribuídas irregularmente, más abundantes sobre la nuca, la coronilla y sobre todo en la región comprendida entre el ojo y la nariz, que a los lados $y$ en la parte inferior, esta piel es de coloración rojo-carmín intenso, pero que varía a voluntad, apareciendo casi blanca algunas reces.

Sobre la parte de la coronilla $y$ la nuca se notan unas áreas sebosas de color amarillo-crema, más notorias en la nuca. La región auricular y hacia la coronilla con matices violáceos o azulados. La cera es también rojo carmín. La abertura de la nariz es muy grande $y$ sin tabique divisorio, formando como un puente a través del cual se ve muy bien al otro lado. El pico está cubierto por la cera en sus dos terceras partes; la parte del extremo es de color de cuerno blanco: más ganchudo que en la especie anterior, aunque más corto y más alto en la base. Los ojos son relativamente pequeños $y$ de color castaño rojizo, pero de expresión muy viva. La parte superior desde la nuca es de coloración negruzca con matices verdes o violeta de brillo metálico. La parte inferior un poco más oscura en el cuerpo, con matices de brillo metŕlico principalmente en el pecho. Las co berteras superiores de las alas están bordeadas de un color castaño amarilloso $\mathrm{y}$ las rémiges primarias y secundarias son de color café-negruzco, con los raquis blancos en su lado inferior y negro brillante en el lado superior, exceptuando las cuatro primeras que tienen raquis amarilloso $y$ las siguientes más oscuras, hasta que las secundarias lo tienen negro, como antes digo, solamente por encima. La cola es asímismo de un color pardo-negro con matices violáceos y los raquis oscuros, por encima. La superficie inferior de las alas y la cola es de coloración mucho más clara, que podría definirse como un blanco sucio, por lo cual estas aves, al ser vistas por debajo, se ven como plateadas al darles el sol en su lado inferior. Por el lado superior se ver como pardas claras. Se destacan muy notoriamente la cabeza rojiza $y$ el pico blanco cuando vuela a poca altura. La cola es más larga y redondeada que la del gallinazo. Las patas son relativamente pequeñas, delgadas y débiles, con escamas pequeñas $y$ dedos armados de nñas poco curvas $y$ afiladas. El dedo posterior es corto, aunque no está situado tan alto como en las especies anteriores. Las patas son de un color rosado pálido sncio $y$ las unas de color de cuerno negro o café.

La apariencia general de esta especie es la de m buitre un poco más grande que el gallinazo, pero más esbelto, con las alas más largas $y$ algo encorvadas en el vuelo.

Nido y huevos. - Construyen su nido en los troncos hue cos, en cavidades de las rocas o sobre el suelo, aunque raras reces hacen un verdadero nido, sino que se contentan con poner sus huevos sobre el fondo desnudo.

Ponen de uno a tres huevos, siendo lo más común dos, algunas veces uno y raramente tres. Los huevos de la guala son de color blanco o crema manchados de café o castaño rojizo, más marcadamente sobre el lado más grueso. Los jóvenes nacen desnudos, pero no tarda en aparecer tn plumón blanco sucio, que es reemplazado más tarde por el plumaje definitivo.

Distribución.-Habita esta especie la parte occidental de Sur América, desde Colombia hasta el Norte de Chile $\boldsymbol{y}$ el occidente de Argentina. Existen otras subespecies afines : ésta: en Norte América Cathartes aura septentrionalis, y en Sur América oriental existe la Cathartes aura ruficollis desde el litoral caribe de Colombia y Veneznela, $y$ las Guayanas hasta el Paraguay.

La guala es quizá una de las aves más hábiles en el arte de volar, $y$ con justicia ha sido tomada como ejemplo en e arte de planear: comisiones de aviadores vinieron de Europa a estudiar estas aves en Venezuela para construír Itégo los veleleros, con que hicieron sus ensayos después en el Brasil. Si la guala en reposo, ya sea en el suelo o sobre 
n árbol, nos parece tan fea, no podemos decir lo mismo en cuanto despliega las alas y se remonta en el espacio, con su suave y lento aleteo, seguido de un largo planear mientras toma altura. Pero una vez que está a suficiente altura para poder aprovechar las corrientes de aire, no vuelve a aletear y solamente el águila puede ganarle en el arte de volar. Como todos sus parientes de este Orden, la guala encuentra su alimento por medio de su agudísima vista y gracias a su gran instinto de observación, pues nada se escapa a su penetrante mirada. Su alimento está formado por carne en descomposición o fresca de cualquier clase de procedencia, desde un pequeño pajarito, hasta los más grandes mamiferos, pero parece tener una marcada tendencia por las pequeñas presas, como perros, gatos, etc. Caza por si misma con gran habilidad las culebras de todas clases, lagartos, sapos, etc. Aunque esta especie es más arisca que la anterior, en ciertas regiones donde es más común que el gallinazo, es bastante confiada.

Es muy frecuente el caso de que la mayor parte de la gente la confunda con el gallinazo, en vuelo o parada, y a esto se debíc la confusión que tuvieron los primeros ornitólogos europeos que vinieron a Sur América; en los libros antiguos no logra uno encontrar las diferencias entre las dos especies.

Como ya he dicho tántas veces en este estudio, las gualas también se observan unas a otras, mientras están volando, muchas veces a gran distancia unas de otras, y cuando una se dirige a tierra, a los pocos minutos van llegando las otras.

Es tan aguda su vista que puede localizar una pequeña presa desde enormes alturas, donde uno no alcanza a verla. Durante el día recorren grandes distancias en busca de alimento. Por la noche se reúnen muchas veces cientos de ellas en los lugares escogidos como dormitorios en el bosque.

Por la mañana, a la salida del sol extienden las alas para calentarse, pero en los días nublados y lluviosos, cuando el aire está quieto permanecen en sus perchas todo el día, pues cuando faltan corrientes de aire les es difícil volar.

Los adultos de estas aves son casi completamente silenciosos, y solamente emiten un leve silbido expulsando el aire de los pulmones a través del tubo respiratorio.

\section{***}

\section{GUALA DE CABEZA AMARILLA}

\section{Cathartes urubitinga Pelzeln.}

Otros nombres: Cabá (Indios cubeos).

La envergadura de la presente especie es de $1,72 \mathrm{~m}$. a $1,85 \mathrm{~m}$. y su longitud de $0,70 \mathrm{~m}, 0,72 \mathrm{~m}$., de los cuales 0,29 m. corresponden a la cola.

Adultos.-La coloración general es negra, con reflejos verde-azulados de brillo metálico. La cabeza y parte del cuello desnudos y de coloración muy variada.

El pico es de color de cuerno blanco, cubierto hasta más adelante de la nariz por la cera de color púrpura, que en la mandíbula inferior es más rojiza. La base del pico y mejilas cubiertas de piel de color amarillo-ocre, casi blanco alrededor de las comisuras del pico. La frente $y$ la parte antero-superior de la cabeza de color rosado-lila pálido. Una mancha o línea transversal azul-plomizo a través de la coronilla, partiendo de la región auricular. Una mancha azul plomo oscuro delante del ojo, de forma triangular. Ojos de color rojo-carmín, relativamente pequeños. Párpados grisáceos. Detrás del ojo y dirigida hacia la región auricular. una manchita negra. Las verrugosidades de la parte posterior de la cabeza y de la nuca de color púrpura-amoratado. La mancha plomiza delante del ojo, la negra de la región auricular, la coronilla, la región occipital y la barba sembradas de plumitas negras en forma de pelos, más abundantes en las dos primeras regiones. Las patas gris-rosado claro. Uñas negras de cuerno.

La superficie inferior de las alas y de la cola de color negro mate plateado; los raquis de las primarias blanco amarillento; los de las secundarias, blanco-amarillento en su parte inferior y la mitad del lado superior desde la punta; el resto es negro brillante. El raquis de las caudales es blanco-amarillento en su lado inferior y negro brillante en la parte superior. Las secundarias y coberteras grandes muestran un notable color violeta-azulado sobre las barbas exteriores, mientras las del lado interior un color verdeoscuro que se pierde hacia el borde, ambos con un hermoso brillo metálico. Las plumas del pecho, los flancos, el vientre y las coberteras inferiores de la cola son también de un negro intenso de reflejos verdes metálicos.

Nidos y huevos. - Al decir de los indios, estas aves anidan de preferencia en huecos de enormes troncos secos abandonados por las guacamayas, o naturales, y muy raramente en el suelo. Ponen por lo general sólo dos huevos de un color rosado muy pálido manchados de pardo oscuro. Los jóvenes están cubiertos al nacer de un plumón color crema sucio.

Distribución.-Esta especie habita el noreste de Venezuela, las Guayanas y el Brasil. Al sur hasta el norte de Argentina $y$ el Uruguay. Fn Colombia son bastante frecuentes en el Vaupés, $y$ algunas llegan por el occidente hasta los Llanos de San Martín y Villavicencio, siendo hasta hace poco esta última localidad la más occidental conocida de su área de dispersión. Pero últimamente la he encontrado en el Valle del Canca y es bastante más pequeña que la del oriente, aunque las características son iguales. $Y$ también en la región de Girardot capturé un ejemplar del mismo tamaño que la del Vaupés; por lo cual supongo que esta especie tiene un área de dispersión bastante extensa en el país.

Las costumbres y género de vida de la especie que nos ocupa son muy poco conocidas, pero se puede afirmar que son habitantes de las selvas de modo especial, y los pocos ejemplares observados en los Llanos siempre han estado en partes cubiertas de bosque, Sin embargo, las del Valle y Girardot estaban en terreno abierto.

Con frecuencia las observaba volando a lo largo de las márgenes del río Vaupés y sus afluentes en busca de alimento, y aunque a primera vista se parece a la especie precedente en el vuelo, se nota una marcada diferencia al observarla con alguna atención.. Su envergadura es un poco mayor; las alas más anchas y especialmente la cabeza, cuya coloración a distancia aparece como amarillo intenso, asi como también la coloración superior de las alas y el cuerpo, que no es parduzca, sino casi completamente negra.

$\mathrm{Su}$ alimento consiste en toda clase de carne muerta y especialmente pescado; por esto se ven reunirse sobre las trampas de madera en forma de andamios y barbacoas que los indios construyen en los raudales de los ríos, que ellos llaman "cachiveras", tomado del brasilero "cahoeira", en la época de la subida de los peces, con el objeto de procurárselos en gran cantidad sin mucho trabajo. En el Valle del Cauca, en la región de Buga, las observé también con régimen alimenticio a base de pescado.

Yo he observado en el sitío llamado Yuruparí, en el río Vaupés, durante muchos días, a estas gualas de cabeza amarilla reunidas alrededor de las trampas en grupos hasta de treinta individuos. Son bastante ariscas y no permiten acercarse mucho. Por las mañanas empezaban a llegar a eso de las siete a las trampas. Después de descansar algunas horas y poco después del medio día, volaban para recorrer los alrededores, regresando al atardecer para comer de nuevo $y$ se retiraban a los árboles secos más altos del bosque al llegar la noche.

Es curioso que nunca, durante un mes de observaciones en las regiones del Vaupés, pude ver a las gualas de cabeza amarilla en unión de las de cabeza roja, ni siquiera en las trampas de pescar. Pero en el Valle y en Girardot sí andan reunidas.

Aunque mis observaciones me permiten decir que la especie de cabeza roja no es frecuente en las regiones selvosas, sino más bien en las estepas y las montañas, diré que eran relativamente frecuentes a lo largo del río Amazonas, donde en cambio nunca vi una de cabeza amarilla.

La especie de cabeza amarilla es poco conocida en Colombia, $y$ los que mejor la conocen en el exterior no la anotan como de nuestro país.

Varios ejemplares fueron capturados, y hasta hace poco existió una viva en el Instituto Botánico de la Universidad Nacional, capturada en las márgenes cubiertas de bosque del río Ocoa, cerca de Villavicencio (Meta).

(Continuará) 